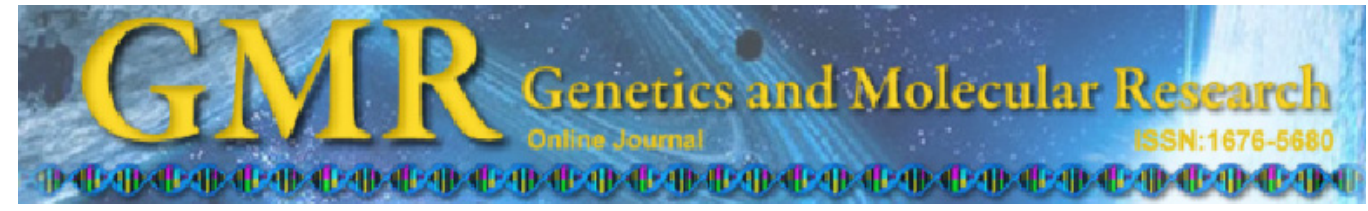

\title{
Vero cells infected with the Lederle strain of canine distemper virus have increased Fas receptor signaling expression at $15 \mathrm{~h}$ post-infection
}

\author{
H.L. Del Puerto' , A.S. Martins', G.F. Braz ${ }^{3}$, F. Alves ${ }^{3}$, M.B. Heinemann ${ }^{3}$, \\ D.S. Rajão ${ }^{3}$, F.C. Araújo ${ }^{4}$, S.F. Martins ${ }^{2}$, D.R. Nascimento ${ }^{2}$, R.C. Leite $^{3}$ \\ and A.C. Vasconcelos ${ }^{1}$ \\ ${ }^{1}$ Departamento de Patologia Geral, Instituto de Ciências Biológicas, \\ Universidade Federal de Minas Gerais, Belo Horizonte, MG, Brasil \\ ${ }^{2}$ Departamento de Fisiologia e Biofísica, Instituto de Ciências Biológicas, \\ Universidade Federal de Minas Gerais, Belo Horizonte, MG, Brasil \\ ${ }^{3}$ Departamento de Medicina Veterinária Preventiva, Escola de Veterinária, \\ Universidade Federal de Minas Gerais, Belo Horizonte, MG, Brasil \\ ${ }^{4}$ Faculdade de Medicina, Medicina Molecular, \\ Universidade Federal de Minas Gerais, Belo Horizonte, MG, Brasil \\ Corresponding author: H.L. Del Puerto \\ E-mail: helendelpuerto@hotmail.com
}

Genet. Mol. Res. 10 (4): 2527-2533 (2011)

Received March 31, 2011

Accepted September 2, 2011

Published October 18, 2011

DOI http://dx.doi.org/10.4238/2011.October.18.3

\begin{abstract}
We evaluated the expression of the Fas receptor gene in Vero cells infected with the Lederle vaccine strain of canine distemper virus using RT-PCR. Vero cells were plated, and after being grown for $24 \mathrm{~h}$ in MEM with 5\% FBS, 80-90\% confluent monolayer cultures were infected with the virus. The cells were harvested at 3, 6, 9, and $15 \mathrm{~h}$ post-infection. Uninfected Vero cells were used as a control. Total RNA was isolated from Vero cells using $1 \mathrm{~mL}$ Trizol ${ }^{\circledR} \mathrm{LS}$, and RT was performed using $2 \mu \mathrm{g}$ total RNA. Primer pairs for RT-PCR amplification for the canine distemper virus nucleocapsid gene, the S26 reference gene, and the Vero rFas gene were used to analyze expression in Vero cells. RT-PCR results revealed virus activity at 3, 6, 9, and 15 $\mathrm{h}$ in the virus-infected Vero cells. The S26 housekeeping gene was
\end{abstract}


amplified in virus infected and control samples. However, expression of the cell death receptor Fas was detected in Vero cells only at $15 \mathrm{~h}$ post-infection. We suggest that the Lederle vaccine induces apoptosis by Fas receptor signaling, possibly through caspase- 8 signaling rather than through mitochondrial signaling in the infected cells.

Key words: Apoptosis; CDV; Fas receptor; RT-PCR; Vero cells

\section{INTRODUCTION}

Apoptosis is a regulated physiological process that plays a critical role in adult tissue homeostasis, and it is involved in embryonic development (Young et al., 1997). The process of apoptosis has also been implicated in the pathogenesis of many infectious diseases including those caused by viruses (Roulston et al., 1999). Apoptotic cells exhibit distinct biochemical and morphological changes such as nuclear shrinkage, chromatin condensation, plasma membrane blebbing, intra-nucleosomal cleavage and, ultimately, the formation of apoptotic bodies due to the fragmentation of DNA strands by activated endogenous endonucleases (Cohen, 1999).

Apoptosis can be triggered through two pathways: the extrinsic pathway and the intrinsic pathway. The extrinsic pathway involves activation of caspase- 8 and is initiated by ligand interaction with Fas or death receptors, while the intrinsic pathway is activated by an imbalance between proapoptotic and antiapoptotic proteins in mitochondria (Merry and Korsmeyer, 1997), resulting in the release of cytochrome $c$ from mitochondria, which in turn activates caspase-9. Both caspase- 8 and caspase- 9 activate caspase- 3 , which along with other effector caspases cleave critical cellular proteins, resulting in apoptosis (Adams, 2003).

Canine distemper virus (CDV), a morbillivirus in the family Paramyxoviridae, causes canine distemper, a severe systemic disease in dogs characterized by a variety of symptoms, including fever, respiratory and enteric signs, and neurologic disorders. It has been reported that CDV causes apoptosis in lymphoid tissue and the cerebellum of infected dogs (Moro et al., 2003a,b; Kumagai et al., 2004), and also in monkey kidney (Vero) cells (Guo and Lu, 2000; Kajita et al., 2006).

It has been demonstrated that CDV infection activates the extrinsic pathway in CDVinfected Vero cells at $24 \mathrm{~h}$ post-infection (p.i.) with activation of caspase- 8 and caspase- 3 and gene expression of Fas death receptor (Kajita et al., 2006). The same mechanism was observed in cerebellum and lymph nodes of naturally infected dogs (Del Puerto et al., 2010). However, no study was performed before $24 \mathrm{~h}$ p.i. to clarify which initial mechanisms are triggered in apoptosis induced by CDV infection.

Thus, the main objectives of this study were to determine the initial mechanisms of apoptosis in cultured Vero cells, a monkey kidney cell line, infected by CDV Lederle strain (CDV-Lederle) and to identify the specific pathways.

\section{MATERIAL AND METHODS}

\section{Cell and virus strains}

Vero cells were plated on 6-well dishes $\left(5 \times 10^{4} \mathrm{cells} / \mathrm{cm}^{2}\right)$, and after being grown for 
$24 \mathrm{~h}$ in modified Eagle's medium with 5\% fetal bovine serum, $80-90 \%$ confluent monolayer cultures were infected with CDV-Lederle at a multiplicity of infection of 0.1 . The cells were harvested for experiments at 3, 6, 9, and $15 \mathrm{~h}$ p.i. Non-infected Vero cells at 3, 6, 9, and $15 \mathrm{~h}$ were used as controls.

\section{RNA isolation}

Total RNA was isolated from CDV-infected Vero cells, and non-infected Vero cells using TRIZOL ${ }^{\circledR}$ reagent and protocol (Invitrogen Life Technologies, Carlsbad, CA, USA). Samples were treated using the TURBO DNA-free kit (AM1907 - Applied Biosystems), and RNA concentration was measured on Nanodrop (Thermo Fisher Scientific, Wilmington, DE, USA).

\section{Reverse transcription (RT)}

The first-strand complementary DNA (cDNA) was synthesized from 400 ng total RNA in a final reaction volume of $20 \mu \mathrm{L}$, using the Superscript first-strand synthesis system (Invitrogen Life Technologies). After denaturing the template RNA and primers (40 pmol Fas receptor, S26 and CDV reverse primers; Table 1) at $70^{\circ} \mathrm{C}$ for $10 \mathrm{~min}, 40 \mathrm{U}$ reverse transcriptase was added in the presence of RT buffer ( $50 \mathrm{mM} \mathrm{KCl}, 20 \mathrm{mM}$ Tris- $\mathrm{HCl}, \mathrm{pH} 8.4), 4 \mu \mathrm{L}$ dNTP mix ( $250 \mu \mathrm{M}$ each), $40 \mathrm{U}$ RNase inhibitor and RNase-free water to complete the final volume. The reaction mixture $(20 \mu \mathrm{L})$ was incubated at $43^{\circ} \mathrm{C}$ for $1 \mathrm{~h}$ and then stopped at $4{ }^{\circ} \mathrm{C}$ and used immediately for polymerase chain reaction (PCR).

\begin{tabular}{|c|c|c|c|c|}
\hline & Primers & Sequence of the nucleotides (nt) & Nucleotide size & Fragment length \\
\hline \multirow[t]{2}{*}{ A } & VCC01-F1 & 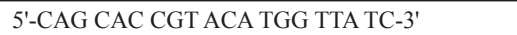 & $20 \mathrm{nt}$ & $319 \mathrm{bp}$ \\
\hline & VVC02-R2 & 5'-TAG CAT AAC TCC AGA GCA ATG-3' & $20 \mathrm{nt}$ & \\
\hline \multirow[t]{2}{*}{ B } & S26CF-F1 & 5'-CGT GCT TCC CAA GCT GTA CGT GA-3' & $24 \mathrm{nt}$ & $75 \mathrm{bp}$ \\
\hline & S26CF-R2 & 5'-CGA TTC CGG ACT ACC TTG CTG TG-3' & $23 \mathrm{nt}$ & \\
\hline \multirow[t]{2}{*}{$\mathrm{C}$} & FasVEROFor & 5'-AAT AAA CTG CAC CCG GAC CCA GAA-3' & $24 \mathrm{nt}$ & $93 \mathrm{bp}$ \\
\hline & FasVERORev & 5'-GTG CAA GGG TCA CAG TGT TCA CAT-3' & $24 \mathrm{nt}$ & \\
\hline
\end{tabular}

Primers used for RT-PCR for canine distemper virus (CDV) diagnosis (A), reference gene S26 (B), and Fas death receptor $(\mathrm{C})$.

\section{Polymerase chain reaction}

PCR amplification for Fas receptor, S26 and the CDV nucleocapsid gene was performed using $40 \mathrm{ng}$ cDNA ( $2 \mu \mathrm{L}$ RT reaction mix), using GoTaq ${ }^{\circledR}$ DNA Polymerase (Promega, WI, USA). PCR was performed in a final volume of $25 \mu \mathrm{L}$, for each target, as follows: 1.25 $\mu \mathrm{L}$ (12.5 pmol) of each primer (reverse and forward) (Table 1), $2 \mu \mathrm{L} \mathrm{dNTP} \mathrm{mix}(0.2 \mathrm{mM}$ each dNTP), $5 \mu \mathrm{L} 5 \mathrm{X}$ GoTaq ${ }^{\circledR}$ DNA Polymerase buffer (final concentration of $1 \mathrm{X}\left(1.5 \mathrm{mM} \mathrm{MgCl}{ }_{2}\right)$ $0.25 \mu \mathrm{L}(2.5 \mathrm{U}) \mathrm{GoTaq}^{\circledR}$ DNA Polymerase and PCR grade water to complete the final volume.

\section{Crystal violet staining}

Vero cell monolayers were washed twice in $1 \mathrm{X}$ PBS, and $400 \mu \mathrm{L}$ crystal violet solution 
was added to each well and allowed to stand for $5 \mathrm{~min}$. After staining, cells were gently washed three times with distilled water, preserving the monolayer. Vero cells were observed using an inverted light microscope, and apoptotic cells were counted using characteristics such as: nuclear shrinkage, chromatin condensation, plasma membrane blebbing, and apoptotic bodies.

\section{RESULTS}

\section{RT-PCR}

RT-PCR results revealed the presence of CDV at 3, 6, 9, and $15 \mathrm{~h}$ in CDV-Lederleinfected Vero cells, and there was no detection in Vero cell control groups. The S26 reference gene was amplified in all samples (Figure 1). However, the gene expression of the death receptor Fas was just detected in Vero cells at $15 \mathrm{~h}$ post-infection (Figure 2). There was no Fas receptor expression in Vero cells at 3, 6 and 9 h p.i.; also, no expression of Fas receptor was observed in Vero cell control groups at 3, 6 and $9 \mathrm{~h}$ (Figure 2).

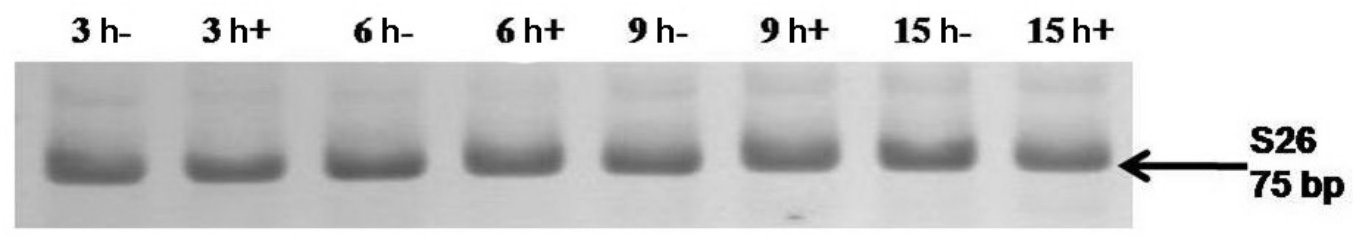

Figure 1. Silver-stained $8 \%$ polyacrylamide gel, after electrophoresis at $100 \mathrm{~V}$ for $50 \mathrm{~min}$. S26 specific amplicon of $75 \mathrm{bp}$ is indicated.

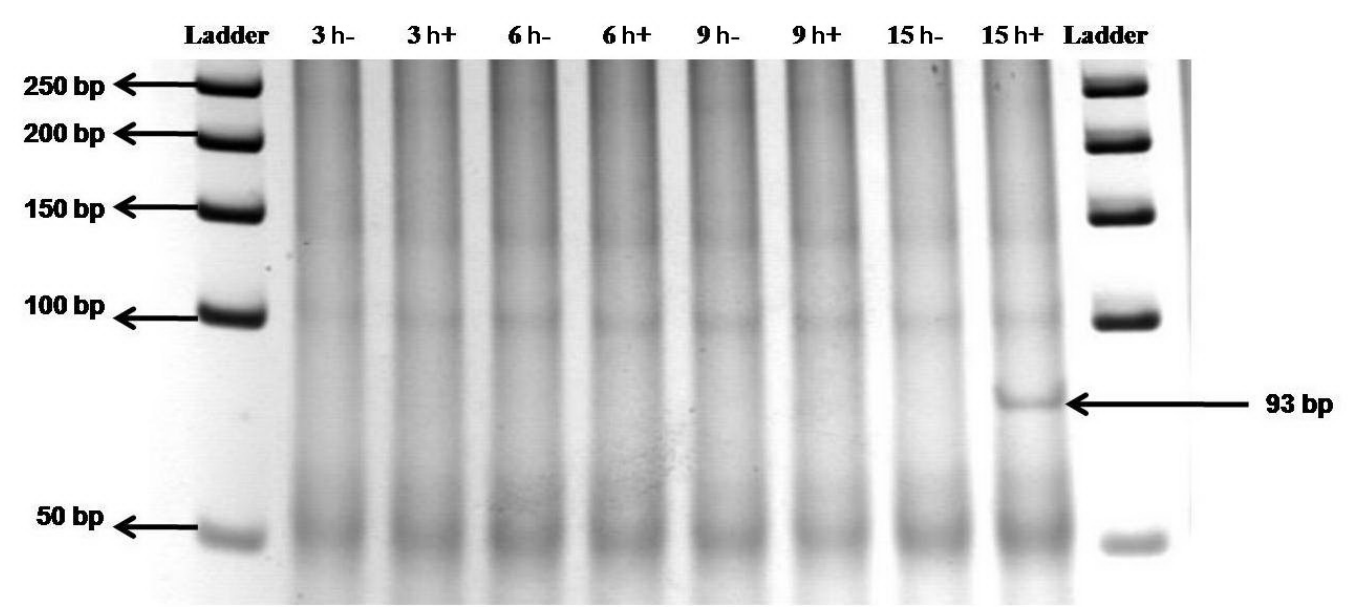

Figure 2. Silver-stained $8 \%$ polyacrylamide gel, after electrophoresis at $100 \mathrm{~V}$ for $50 \mathrm{~min}$. Fas receptor specific amplicon of $93 \mathrm{bp}$ is indicated, and it is shown at $15 \mathrm{~h}$ after CDV infection sample $(15 \mathrm{~h}+)$. Ladder $=50$-bp DNA $(0.3 \mu \mathrm{g})$. 


\section{Crystal violet staining}

Crystal violet staining revealed typical apoptosis morphology in Vero cells at 3, 6, 9, and $15 \mathrm{~h}$ p.i. (Figure 3). Upon quantification of approximately 100 cells, the apoptotic rate was found to be $11 \%$ at $3 \mathrm{~h}$ p.i., $16 \%$ at $6 \mathrm{~h} \mathrm{p.i.,} 23 \%$ at $9 \mathrm{~h}$ p.i., and $34 \%$ at $15 \mathrm{~h} \mathrm{p.i.} \mathrm{Vero} \mathrm{cell}$ control groups did not show apoptotic cells. This indicated that CDV induces apoptosis of Vero cells in a time-dependent way.

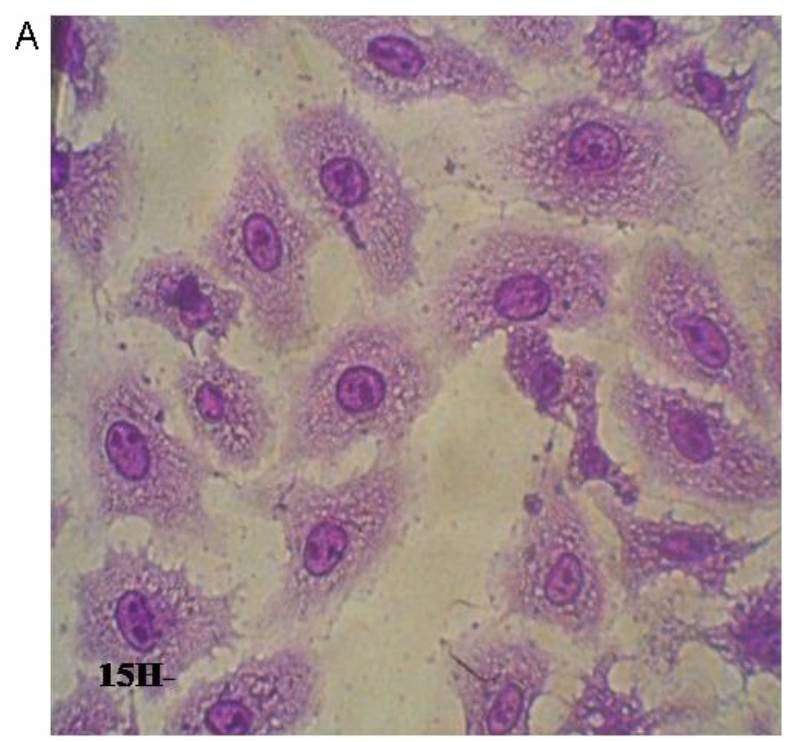

B

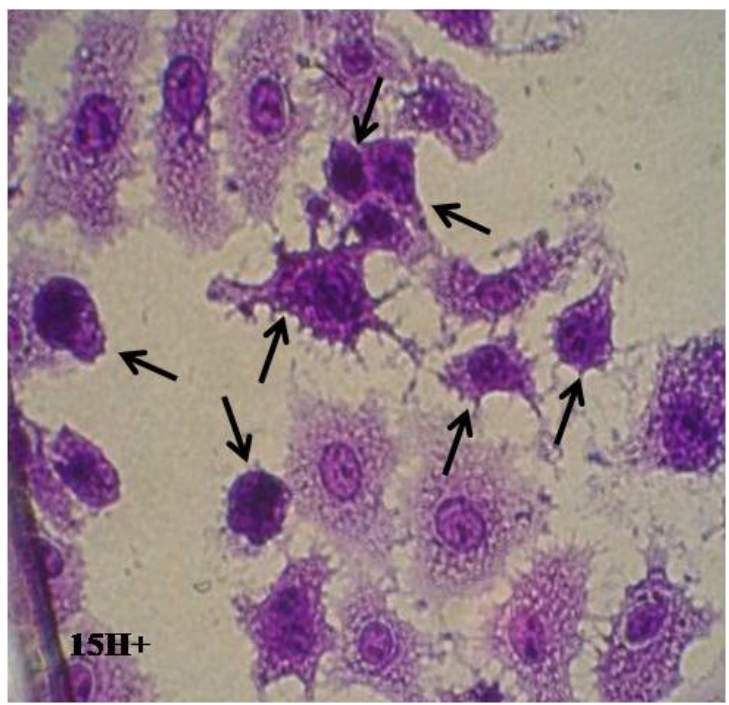

Figure 3. A. Control Vero cells (CDV non-infected) at $15 \mathrm{~h}$. B. CDV-infected Vero cells at 15 h post-infection. Arrows indicate apoptotic cells. 


\title{
DISCUSSION
}

In the present study, Vero cells infected by CDV-Lederle showed typical apoptosis morphology at different p.i. times, indicating that CDV-Lederle induced apoptosis in Vero cells, while no apoptotic cells were identified in control Vero cell groups.

In the present study, it was also found that CDV-Lederle cells at $15 \mathrm{~h}$ p.i. expressed Fas death receptor mRNA (Figure 2). Taken together, these findings indicate the possibility that CDV-Lederle infection may activate Fas-mediated caspase-8 signaling to induce apoptosis in Vero cells. Interestingly, there has been no report that Vero cells express FasL, so it seems unlikely that apoptosis in CDV-infected Vero cells was triggered by the FasL-bound Fas receptor. In the case of measles virus (MV), which belongs to the genus Morbillivirus, MV-infected peripheral blood mononuclear cells (Vuorinen et al., 2003) and dendritic cells (Servet-Delprat et al., 2000a) have been shown to induce apoptosis in uninfected T cells via the Fas/FasL pathway (Servet-Delprat et al., 2000b). With respect to the Sendai virus (Sv), which, like CDV, belongs to the subfamily Paramyxovirinae, it has been reported that induction of host cell apoptosis by Sv in vitro requires the activation of caspase- 8 but does not require FasL (Bitzer et al., 1999). Our results revealed Fas receptor mRNA expression only at $15 \mathrm{~h}$ p.i. However, apoptotic cells were observed at 3, 6 and 9 h p.i., while no Fas receptor mRNA expression was demonstrated during these times. Therefore, it can be considered that during virus replication and infection, the cells' injury induced mRNA expression of the Fas receptor at $15 \mathrm{~h}$ p.i., and as reported by Kajita et al. (2006), this can persist up to $48 \mathrm{~h}$ p.i. Further studies will be needed to clarify the mechanisms of CDV-induced host cell apoptosis at initial times of infection and to determine if the initial apoptosis mechanisms induced by CDV trigger the intrinsic pathway, and later the extrinsic pathway.

In conclusion, CDV-Lederle was found to induce apoptosis in Vero cells by activating the extrinsic pathway at $15 \mathrm{~h}$ p.i., and the principal cascade for this induction occurred along the caspase- 8 activation pathways. Based on the present findings, the mitochondrial pathway may not participate in the caspase-8/caspase-3-mediated induction of apoptosis after $15 \mathrm{~h}$ p.i., but it is not clear if the mitochondrial pathway participates at the initial times of CDV infection. Further studies will be necessary to clarify the detailed mechanisms by which apoptosis is induced in CDV-infected cells.

\section{ACKNOWLEDGMENTS}

\author{
Research supported by CNPq and FAPEMIG.
}

\section{REFERENCES}

Adams JM (2003). Ways of dying: multiple pathways to apoptosis. Genes Dev. 17: 2481-2495.

Bitzer M, Prinz F, Bauer M, Spiegel M, et al. (1999). Sendai virus infection induces apoptosis through activation of caspase-8 (FLICE) and caspase-3 (CPP32). J. Virol. 73: 702-708.

Cohen JJ (1999). Apoptosis: mechanisms of life and death in the immune system. J. Allergy Clin. Immunol. 103: 548-554. Del Puerto HL, Martins AS, Moro L, Milsted A, et al. (2010). Caspase-3/-8/-9, Bax and Bcl-2 expression in the cerebellum, lymph nodes and leukocytes of dogs naturally infected with canine distemper virus. Genet. Mol. Res. 9: 151-161.

Guo A and Lu C (2000). Canine distemper virus causes apoptosis of Vero cells. J. Vet. Med. B. Infect. Dis. Vet. Public Health 47: 183-190.

Kajita M, Katayama H, Murata T, Kai C, et al. (2006). Canine distemper virus induces apoptosis through caspase-3 and -8 
activation in vero cells. J. Vet. Med. B. Infect. Dis. Vet. Public Health 53: 273-277.

Kumagai K, Yamaguchi R, Uchida K and Tateyama S (2004). Lymphoid apoptosis in acute canine distemper. J. Vet. Med. Sci. 66: 175-181.

Merry DE and Korsmeyer SJ (1997). Bcl-2 gene family in the nervous system. Annu. Rev. Neurosci. 20: 245-267.

Moro L, Martins AS, Alves CM, Santos FG, et al. (2003a). Apoptosis in the cerebellum of dogs with distemper. J. Vet. Med. B. Infect. Dis. Vet. Public Health 50: 221-225.

Moro L, de Sousa MA, de Moraes AC, de Araujo Santos FG, et al. (2003b). Apoptosis in canine distemper. Arch. Virol. 148: 153-164.

Roulston A, Marcellus RC and Branton PE (1999). Viruses and apoptosis. Annu. Rev. Microbiol. 53: 577-628.

Servet-Delprat C, Vidalain PO, Azocar O, Le Deist F, et al. (2000a). Consequences of Fas-mediated human dendritic cell apoptosis induced by measles virus. J. Virol. 74: 4387-4393.

Servet-Delprat C, Vidalain PO, Bausinger H, Manie S, et al. (2000b). Measles virus induces abnormal differentiation of CD40 ligand-activated human dendritic cells. J. Immunol. 164: 1753-1760.

Vuorinen T, Peri P and Vainionpaa R (2003). Measles virus induces apoptosis in uninfected bystander T cells and leads to granzyme B and caspase activation in peripheral blood mononuclear cell cultures. Eur. J. Clin. Invest. 33: 434-442.

Young LS, Dawson CW and Eliopoulos AG (1997). Viruses and apoptosis. Br. Med. Bull. 53: 509-521. 